\title{
Selective attentional bias to food-related stimuli in healthy individuals with characteristics towards orthorexia nervosa
}

\author{
Ian P. Albery ${ }^{1}\left[\right.$ $\cdot$ Monika Michalska ${ }^{1} \cdot$ Antony C. Moss ${ }^{1} \cdot$ Marcantonio Spada $^{1}$
}

Received: 10 April 2019 / Accepted: 18 July 2019 / Published online: 27 July 2019

(c) The Author(s) 2019

\begin{abstract}
Purpose It has been argued that orthorexia nervosa $(\mathrm{ON})$ is a unique type of disordered eating of food considered by the individual to be healthy. Given that in other eating disorder populations attentional preference for food-related cues influences eating behaviours, is it also likely that these biases may be a characteristic of ON tendency.

Methods Eighty healthy individuals completed the ORTO-15 questionnaire (ON tendency), a modified Stroop task containing words related to healthy and unhealthy foods and perceived hunger levels pre- and post-testing. The ORTO-15 was used to identify participants within this sample who demonstrated more or less of the characteristics of ON.

Results Results suggest that the presence of attentional bias to healthy, but not for unhealthy food-related stimuli independently predict increased ON tendency. Increased attentional bias towards healthy food-related stimuli is associated with increased scores on the ORTO-15.

Conclusion Attentional bias, as a deficit in information processing, towards healthy food-related stimuli accounts for variability in ON characteristics.

Level of evidence Level I, experimental study.
\end{abstract}

Keywords Orthorexia nervosa $\cdot$ Attentional bias $\cdot$ ORTO-15 $\cdot$ Stroop-task

\section{Introduction}

Orthorexia nervosa $(\mathrm{ON})$ is characterized by obsessive and selective eating behaviour which may lead to malnutrition and significant negative effects on social and occupational functioning [1]. ON tendencies have been measured in a variety of populations including medical students [2], nutritionists [3], dietitians [4], medical doctors [5], performance artists [6], athletes [7] and yoga practitioners [8]. Orthorexia nervosa does not appear to be age-related [9] and the evidence base with respect to gender disparities is at present equivocal $[7,10,11]$.

The symptomatology of $\mathrm{ON}$ varies across the literature, but diagnostic criteria generally include severe dietary

This article is part of topical collection on Orthorexia Nervosa.

Ian P. Albery

alberyip@1sbu.ac.uk

1 Centre for Addictive Behaviours Research, School of Applied Sciences, London South Bank University, London, UK restrictions, excessive time spent on preparing and shopping for food, increased spending, preoccupation with purity and provenance of ingredients, eating alone, feelings of guilt if non-adherent, and perceived superiority over others when adherent [12]. With a significant increase of ON-specific issues being reported by eating disorder professionals [13], calls have been made for the formal inclusion of $\mathrm{ON}$ into diagnostic manuals [14].

Whilst it has been argued that $\mathrm{ON}$ is a unique and specific eating disorder $[12,15,16]$, a number of studies have identified common affective and cognitive agents operating in $\mathrm{ON}$, obsessive-compulsive disorder (OCD) and other eating disorders [17, 18]. More specifically, it has been suggested that anxious states similar to those reported by people with anorexia nervosa (AN) and OCD (strong beliefs about food and obsessive eating habits) may be characteristic of ON [19, 20] and lead to "health anxiety" [21]. Moreover, in contrast to body image and weight-related concerns, which are prevalent in AN and bulimia nervosa [22], over exercising and weight loss do not seem to be the main objectives of those experiencing $\mathrm{ON}$, although unintentional weight loss might result from highly selective eating [23-25]. 
Interestingly, the presence or absence of $\mathrm{ON}$ does not seem to be associated with body mass index $[26,27]$. There is also the tendency for those with $\mathrm{ON}$ to report the experience of positively valanced emotions associated with one's body image, attachment style perfectionism, increased self-esteem and narcissism [28].

With the recent growth of the health-food sector, an everincreasing presence of healthy eating promotional information in the mass and social media $[29,30]$ and evidence that more restrictive eating (such as that adopted in vegetarianism) may be associated with increased ON likelihood [31], understanding those psychological processes linked to the development and maintenance of ON-related behaviours is of increasing importance. One prediction suggests that, for example, that like other eating disorders, ON may be characterized by the inability to adapt thinking to newly encountered information/events. This cognitive inflexibility, however, was not shown to be characteristic of ON compared to controls [16, 32].

An alternative information processing bias that has been shown to play a fundamental role in a number of eating disorders concerns how attentional biases influence the processing of concern-related stimuli [33, 34]. This might be another candidate starting point for delineating characteristics of ongoing ON-related thought. Various cognitive models suggest that attentional bias helps to establish and maintain eating disorders and other forms of appetitive behaviours $[34,35]$ by inducing distractibility and attentional approach towards concern-related environmental cues [36-38], which after repeated exposure becomes unconscious [39]. This is comparable with hyper-vigilance and craving induced by automatic biased processing seen in substance dependence [39, 40], gambling [41] and various other compulsive and habitual health-related behaviours [40, 42].

Attentional bias research employs a variety of experimental paradigms (e.g. visual probe, eye tracking) with the modified Stroop task showing that people with eating disorders tend to respond slower than a control group to concern-related words in clinical and non-clinical populations [see 43, 44 for meta-analyses, 33, 45]. Importantly, recent evidence suggests that these effects are associated with ongoing related behaviours such as purging in bulimia nervosa [36]. Theoretically it has been argued that impaired attentional processing and appetitive responses to concernrelated information may lead to the systematic strengthening of dopaminergic or "pleasure" neurobiological pathways and also craving-induced sensitization [39]. This may lead to increased saliency of interest-related cues and to a heightened "need" to consume, for example, particular food stuffs to increase positive and minimize negative affective states $[46,47]$. To date, no work has examined the operation of attentional biases in relation to individual differences in ON-related psychological tendency. It would be plausible to expect, however, that people with an increased tendency towards ON may respond differently to food-related words relative to those with decreased $\mathrm{ON}$ tendencies. More specifically, it is predicted that those with increased ON tendencies will show interference to healthy-related words, a pattern of results not predicted for those with decreased ON tendencies. To explore the operation of preferential attention to food-related stimuli, the present study examined the relationship between $\mathrm{ON}$ tendencies and attentional biases for healthy and unhealthy related food words.

\section{Methods}

\section{Design}

The study used a correlational design with attentional bias scores (mean correct responses in milliseconds [ms]) derived from two modified food-Stroop tasks as independent variables and ORTO-15 scores as the dependent variable. Attentional bias $(\mathrm{AB})$ scores were derived by subtracting mean correct reaction times $(\mathrm{ms})$ for neutral words from mean correct reaction times for their matched healthy and unhealthy words (see Table 1 for means and standard deviations). Scores greater than zero represent increased interference from healthy/unhealthy words. Words for inclusion in the Stroop tasks were derived from a pilot study (see "Procedure" section).

\section{Participants}

Eighty participants ( 20 males and 60 females) aged between 18 and 58 years (mean age $=29.43$; sd $=10.6$ ) took part in the main study. Forty-five $(56.3 \%)$ participants were recruited from undergraduate students at a London university in return for course credit, and the remainder $(n=35$, $43.7 \%$ ) were members of the public recruited from the local area.

Table 1 Millisecond mean correct reaction times (standard deviations in parentheses) and attentional bias scores for healthy, unhealthy and matched neutral food-related word types

\begin{tabular}{llllll}
\hline \multicolumn{6}{l}{ Word type } \\
\hline Healthy & $\begin{array}{l}\text { Matched } \\
\text { neutral }\end{array}$ & AB score & Unhealthy & $\begin{array}{l}\text { Matched } \\
\text { neutral }\end{array}$ & AB score \\
\hline 724.21 & 698.67 & $+25.54^{*}$ & 707.02 & 723.42 & -16.40 \\
$(132.32)$ & $(148.50)$ & $(94.42)$ & $(160.93)$ & $(161.08)$ & $(79.42)$ \\
\hline
\end{tabular}

$N=80$

$* p<0.05$ one-sample $t$ test against zero 


\section{Materials}

\section{Deriving words for use in the healthy and unhealthy food Stroops}

Two groups of five participants were recruited for a twostage pilot phase and comprised individuals approached by the researcher at various locations such as health food stores and gyms in London. These individuals did not take part in the main study. Initially, in the first stage five individuals were asked to generate as many words related to the categories "healthy" and "unhealthy" food (categories were counterbalanced) as possible in $3 \mathrm{~min}$. A second group of five individuals were then asked to rate these 48 words for their category representativeness and familiarity. The 48 words had been reported by at least three of the five participants in stage 1 ( 25 healthy and 23 unhealthy words). For each word participants were presented with the statements: "This word is related to healthy/unhealthy food and eating habits" and "I am familiar with this word" and asked to rate the extent to which they agreed or disagreed with each on a 5-point Likert scale $(1=$ strongly disagree to $5=$ strongly agree $)$. The next phase examined how the pilot participants rated the healthiness and desirability of each word using a 5-point Likert scale $(1=$ very healthy to $5=$ very unhealthy and $1=$ very undesirable to $5=$ very desirable). All the words were presented to participants in a random order. Desirable unhealthy words and undesirable healthy words were discarded (e.g. raw). The final set of five words for each of the unhealthy and healthy word categories consisted of those rated the highest for familiarity, category representativeness, healthiness/unhealthiness and desirability for healthy and unhealthy words. The neutral category constituted words representing "things found in the office" [48] and were matched with the food-related words for their length and frequency. This resulted in the following categories: healthy food-related words-fresh, vegetables, whole, salad and natural; healthy food-matched neutral words-files, calculator, ruler, paper, and printer; unhealthy food-related words-processed, greasy, fried, salt, takeaway; unhealthy food-matched neutral words-envelope, pencil, chair, lamp, blinds.

\section{ORTO-15}

Participants also completed the ORTO-15 questionnaire comprising 15 items addressing cognitive, emotional and clinical factors arising from ON. For example: "Are your eating choices conditioned by your worry about your health status?"; "Is the taste of food more important than the quality when you evaluate food?". Answers were given on a four-point Likert scale $(1=$ always to $4=$ never $)$. Low scores indicate increased ON tendency. ORTO-15 has been used to assess the prevalence of $\mathrm{ON}$ behaviours across a variety of clinical [7] and non-clinical populations [49].

\section{Current hunger}

Participants rated their current levels of hunger on a 5-point Likert scale ('strongly disagree' to 'strongly agree)' in response to two statements: "At the moment I feel hungry" and "At the moment I do not feel hungry" before and after the administration of the Stroop task. These variables were measured to ascertain any change pre- and post-Stroop administration.

\section{Procedure}

Following consent, participants initially rated their current hunger levels and then completed the two modified Stroop tasks tomeasure attentional preference separately for unhealthy-related and healthy-related food words. Presentation order of Stroop type was counterbalanced across participants. For each experimental session, participants completed two blocks of practice trials ( 40 trials prior to each experimental block) in which non-word letter strings (e.g. XXXY, YYYY) were displayed in any one of four colours (blue, green, red, yellow). Participants then completed healthy and unhealthy food Stroops in a counterbalanced order. In each of the two Stroop tasks participants were presented with either healthy or unhealthy words, and their matched neutral healthy or matched neutral unhealthy words in each of the four colours. All stimuli were presented in blocks. Participants were asked to ignore the word and respond to the colour in which the word was presented by pressing one of four keys labelled with the colour name. Each word appeared in the centre of the computer screen until a key response was made at which point the next word appeared. Across a total of 120 trials within healthy/unhealthy and matched neutral blocks, words were presented randomly in each of the fours colours and repeated three times (60 trials for each of the healthy and unhealthy blocks and 60 trials for each of the matched healthy and matched unhealthy blocks). Total number of trials per participant was 240 trials. Words were presented using ePrime (Psychology Software Tools Inc., Pittsburgh, Pennsylvania) and conducted on a 13.3-in. Lenovo laptop with an LCD screen. Accuracy and reaction time (millisecond) for each word was recorded. Participants then completed the second current hunger questionnaire and the ORTO-15. Completion of these questionnaires after the Stroop tasks aimed to eliminate possible priming of foodrelated content on subsequent performance. All testing took place in a single occupancy quiet room or experimental cubicle. 


\section{Results}

Initial analysis of the overall sample $(N=80)$ showed that ORTO- 15 scores ranged between 27 and 45 (mean $=36.93$; $\mathrm{sd}=4.45)$. An independent samples $t$ test revealed no significant differences between males and females $(t(78)=1.030$, $p=0.88)$, nor any correlation between age and the ORTO15 scale scores $(r=0.02, p=0.151)$. In addition, across all participants the mean $\mathrm{AB}$ score for healthy food-related words (mean $=25.54$, sd $=94.42$ ) was shown to differ significantly from zero (the point of no difference in response speeds to these stimuli), $t(79)=2.42, p<0.05$. This was not shown for mean $\mathrm{AB}$ score for unhealthy food-related words, $t(79)=1.85, p>0.05$. The size of the bias for healthy words was also significantly greater than for unhealthy words, $t(79)=3.23, p<01$.

To examine the predictive relationship between attentional bias scores above and beyond current hunger status and ORTO-15 scores for the sample as a whole and for those scoring below the ORTO-15 cut-off of 40 (indicative of increased ON tendencies), hierarchical multiple regressions were used. In each regression ORTO-15 scores were the criterion factor with change in hunger level entered at the first step and attentional bias scores at the second step. Prior to analyses all assumptions for the use of multiple regression were assessed.

\section{Predicting ORTO-15 scores}

Pearson's $r$ correlational coefficients were calculated between the criterion variable and possible predictor variables for justification of inclusion in the analysis. Only those variables significantly correlated with ORTO-15 were included in the main analysis (see Table 2). Prior to the hierarchical multiple regression, relevant assumptions for this test were examined. First of all, a sample size of 80 was adequate given two independent variables entered into the analysis [50]. Table 2 shows that the two variables shown to correlate with ORTO-15, change in hunger levels pre- and post-testing and $\mathrm{AB}$ scores for healthy food-related words,

Table 2 Pearson's $r$ correlational coefficients for current hunger change score, $\mathrm{AB}$ for healthy and unhealthy-related words and ORTO-15 scores

\begin{tabular}{lccl}
\hline & Hunger change & AB healthy & AB unhealthy \\
\hline ORTO-15 score & $-0.33^{* *}$ & $-0.26^{*}$ & 0.03 \\
Hunger change & & 0.04 & 0.15 \\
AB healthy & & & 0.12 \\
\hline
\end{tabular}

$N=80$

${ }^{*} p<0.05, * * p<0.01$ were not correlated with each other and collinearity statistics were within acceptable limits suggesting low multicollinearity-tolerances $>0.10$; average VIF $<10$. Mahalanobis distance scores showed there to be no multivariate outliers and residual and scatterplots suggested that normality, linearity and homoscedasticity assumptions were met.

We then used a hierarchical multiple regression to examine the effects of attentional bias scores on ORTO-15 scores controlling for change in hunger levels pre- and post-testing. Specifically, change in hunger level was entered at the first step in predicting ORTO- 15 and AB scores for healthy food-related words added to the equation in the second step. At step one, change in hunger level was shown to significantly predict ORTO-15 scores, $F(1,78)=9.21, p<0.01$, $R^{2}=0.11$, adj $R^{2}=0.09$. At step 2 , adding $\mathrm{AB}$ scores for healthy food-related words to change in hunger level also significantly predicted ORTO- 15 scores, $F(2,77)=7.61$, $p<0.001, R^{2}=0.17$, adj $R^{2}=0.14$. The addition of $\mathrm{AB}$ scores for healthy food-related words significantly increased the proportion of variance explained in ORTO-15 scores, $\Delta F(1,77)=5.48, p<0.05, \Delta R^{2}=0.06$. When both predictor variables were included in the equation both change in hunger level $(\beta=-0.32,95 \%$ CIs $[-3.85,-0.79])$ and $\mathrm{AB}$ scores for healthy food-related words $(\beta=-0.24,95 \%$ CIs $[-0.02,-0.002])$ were shown to both predict ORTO15 scores $(p s<0.05)$ and uniquely accounting for $10 \%$ and $6 \%$, respectively, of the variation in ORTO-15 scores (see Table 3).

\section{Predicting ORTO-15 scores less than 40}

Our final analyses examined the relationship between ORTO-15 scores as a criterion factor and relevant predictor variables among those scoring either above $(n=56)$ or below $40(n=24)$ on the OTRO-15 as a threshold for ON risk [see 51]. For those scoring below 40 (higher in ON risk), initial Pearson's $r$ correlations showed ORTO- 15 to be significantly associated with change in hunger status $(r=-0.34, p<0.01)$ and $\mathrm{AB}$ scores for healthy words $(r=-0.31, p<0.05)$ but not $\mathrm{AB}$ for unhealthy words $(r=-0.01, p=0.95)$. The sample size of 50 was adequate given two independent variables entered into the analysis [50]. An assessment of assumptions for linear regression analysis showed that the relationship between change in hunger levels and $\mathrm{AB}$ scores for healthy food-related words were not correlated $(r=-0.01$, $p=0.98$ ), collinearity statistics were within acceptable limits suggesting low multicollinearity (tolerances $>0.10$; average VIF < 10), Mahalanobis distance scores showed there to be no multivariate outliers, and residual and scatterplots suggested that normality, linearity and homoscedasticity assumptions were met. The same regression analysis as that reported previously was then performed for the sub-sample. 
Table 3 Summary of hierarchical regression analysis for variables predicting ORTO15 scores

\begin{tabular}{|c|c|c|c|c|c|c|}
\hline Variable & $\beta$ & $t$ & $\mathrm{sr}^{2}$ & $R$ & $R^{2}$ & $\Delta R^{2}$ \\
\hline Step 1 & & & & 0.33 & 0.11 & 0.11 \\
\hline Change in hunger & -0.33 & $3.04 * *$ & 0.11 & & & \\
\hline Step 2 & & & & 0.41 & 0.17 & 0.06 \\
\hline Change in hunger & -0.32 & $3.03 * *$ & 0.10 & & & \\
\hline $\mathrm{AB}$ healthy food words & -0.24 & $2.34 *$ & 0.06 & & & \\
\hline
\end{tabular}

At step one, change in hunger level was shown to significantly predict ORTO-15 scores, $F(1,54)=6.89, p<0.05$, $R^{2}=0.11$, adj $R^{2}=0.10$. At step 2 , adding $\mathrm{AB}$ scores for healthy food-related words to change in hunger level also significantly predicted ORTO-15 scores, $F(2,53)=7.10$, $p<0.01, R^{2}=0.21$, adj $R^{2}=0.18$. The addition of $\mathrm{AB}$ scores for healthy food-related words significantly increased the proportion of variance explained in ORTO-15 scores, $\Delta F$ $(1,53)=6.59, p<0.01, \Delta R^{2}=0.10$. When both predictor variables were included in the equation change in hunger level $(\beta=-0.34,95 \%$ CIs $[-3.13,-0.499])$ and $A B$ scores for healthy food-related words $(\beta=-0.31,95 \%$ CIs $[-0.02,-0.002])$ were shown to both predict ORTO15 scores $(p s<0.01)$ and uniquely accounted for $12 \%$ $(\mathrm{sr}=-0.34)$ and $10 \%(\mathrm{sr}=-0.31)$, respectively, of the variation in ORTO-15 scores.

Regression analysis for those scoring above 40 (lower in ON risk) was not performed because initial Pearson's $r$ correlation showed ORTO-15 to correlate significantly with AN for unhealthy words $(r=-0.53, p<0.10)$, but not with change in hunger $(r=0.18, p=0.39)$ nor $\mathrm{AB}$ for healthy words $(r=0.01, p=0.98)$.

\section{Discussion}

This study employed a modified food-Stroop task to assess the relationship between attentional preference for healthy/ unhealthy food-related words over matched neutral words and $\mathrm{ON}$ tendency scores in a non-clinical sample of individuals. ON tendencies was based on responses to the ORTO15 [51], a measure previously used to assess the prevalence of ON-related behaviours across a variety of clinical and non-clinical populations [7, 49]. Results showed that, in general, individuals showed a significant attentional preference for healthy food-related words and not unhealthy food-related words, and that the magnitude of this bias was significantly greater for healthy relative to unhealthy words. Participants showed significantly greater interference from healthy food-related words relative to unhealthy food-related words. This suggests that the general pattern of responding, irrespective of ON tendencies, is for people to show a pattern of responding consistent with an attentional bias for healthy food-related words and that this bias is larger when compared with responses to unhealthy food-related words.

Our next question was to ask whether this pattern of responding was associated with individual differences in ON tendencies. The initial prediction was that relative to participants with decreased ON tendencies, people with higher ON tendencies would show an increased attentional bias for food-related healthy words and not for unhealthy food-related stimuli. This was supported in the current study. Only AB for healthy food-related words were found to be significantly associated with ORTO-15 scores. The negative correlation shows that increased $\mathrm{ON}$ tendencies are associated with increased attentional preference for healthy food-related words. Our findings also showed that attentional preference for healthy food-related words is a significant independent predictor of ON tendencies over and above other variables. In our study, we measured levels of hunger pre- and post-modified Stroop to control for the idea that performing the Stroop itself could act as a prime for beliefs about one's hunger to the extent that this then accounts for any variability in reported ON tendencies. The hierarchical regression analysis did indeed show that change in hunger status was significantly predictive of $\mathrm{ON}$ tendencies with increased $\mathrm{ON}$ tendencies associated with increased hunger post-Stroop. However, it also highlighted that attentional bias scores for healthy food-related words added significantly more variance explained in ORTO-15 than that explained by change in hunger status alone. Moreover, the proportion of unique variance explained by $A B$ for healthy food-related words was significant $(\beta=-0.24$, $\left.\mathrm{sr}^{2}=0.06\right)$. Notwithstanding debate around the categorization of ON via various psychometric measures (see [62]), that we derived an identical set of findings among those who would be deemed as $\mathrm{ON}$ according to recommended ORTO-15 scores [51], but not for those who scored above this threshold is not without significance. Indeed, the amount of unique variance accounted for by $\mathrm{AB}$ for healthy words was shown to increase $\left(\beta=-0.31, \mathrm{sr}^{2}=0.10\right)$. This shows that the relationship between increasing $A B$ for healthy 
food-related stimuli and $\mathrm{ON}$ tendencies is magnified further among those who may already be so characterized. The question as to whether this relationship is linear or more curvilinear in nature requires future investigation. One possibility is that this relationship is an incremental increase in both $\mathrm{AB}$ and $\mathrm{ON}$ severity. An alternative possibility is that increasing $\mathrm{AB}$ is more crucial in the earlier stages of $\mathrm{ON}$ severity compared to a more chronic ON phase.

Overall, this evidence suggests that cognitive markers of attentional preference for healthy food-related words are incrementally discriminative with increasing ON-related tendencies (i.e. ORTO-15 scores). These findings are novel in the ON literature and adhere to the pattern of findings found utilizing a modified Stroop task to assess responses to concern-related stimuli in overweight and normal-weight individuals. In essence, these groups show elevated attentional bias for food-related words [52, 53], which may predict subsequent weight gain [54].

Moreover, our evidence is consistent with the general idea that people tend to show increased attentional preference for stimuli that are of more "concern" for them and that these information processing biases occur during ongoing experience a position reflected in empirical evidence and theoretical approaches for understanding numerous behaviours [36, $38,55,56]$. These information processing accounts argue that with repeated behavioural experience concern-related stimuli are detected automatically (without conscious awareness) and may trigger desire-related thoughts and ongoing behavioural patterns $[39,40]$. In the case of individuals with higher tendencies towards ON, it is likely that with repeated experience of relevant behaviour, healthy food-related stimuli are more likely to catch the attentional system (i.e. are more salient for processing) relative to non-concern-related stimuli and that such attentional processing operates outside of one's immediate awareness. We are not, however, stating any causal relationship. Our data suggest a relationship only and future prospective work or experimental manipulation of such biases is required to determine causality. For instance, studies which have either (1) manipulated such biases through intervention and measured subsequent behaviour $[57,58]$ or (2) prospectively predicted relapse behaviour from known bias levels $[59,60]$ for numerous addictive behaviours show equivocal evidence. On this basis, it has been argued that attentional bias may not be a stable intrinsic characteristic which influences behavioural enactment processes but should be considered as operating in-the-moment immediately prior to behaviour [61].

The current study also showed that ON tendency was not associated with response patterns to unhealthy words relative to neutral controls to the extent that there was no statistically significant interference from these stimuli. A priori it may have been expected that such an interference would have been shown with increasing $\mathrm{ON}$ tendency because these stimuli may be more "threatening" in nature and to be avoided [38,61]. That this was not the case argues against this perspective. It seems that among those with increasing $\mathrm{ON}$ tendencies, the attentional system is more finely tuned to the extent that it is specific to healthy food-related stimuli.

An alternative explanation for the operation of the bias towards healthy and not unhealthy food-related words as a function of increasing $\mathrm{ON}$ tendencies proposes that whilst healthy stimuli are of concern this concern may best be reflected as a form of desire. Whilst desire was not explicitly measured, we did measure beliefs about changes in levels of hunger pre- and post-Stroop task. If we assume that degree of in-the-moment hunger acts as a proxy for desire, we would expect a significant association between healthy food-related interference and change in hunger experienced. In other words, attentional biases should trigger feelings or thoughts associated with hunger. This was not found to be the case. Both in-the-moment change in hunger and $\mathrm{AB}$ for healthy food-related words independently predicted ORTO15 , with $\mathrm{AB}$ for healthy words adding significantly explained variance in ORTO- 15 beyond that explained by change in hunger alone. To test this idea further future work is required to assess more precisely the desire/urge responding for healthy food-related stimuli among those with increased ON tendencies and how information processing biases (approach-avoidance bias, attentional bias, etc.) may influence this relationship.

These study findings may be tempered by a number of apparent limitations. First of all, whilst the ORTO-15 is a widely used measure of $\mathrm{ON}$ tendencies, recent debate has questioned its psychometric properties [62]. Future work should examine the effect of information processing biases using alternative measures of ON. Three possible candidates are the Eating Habit Questionnaire (EHQ) [63], Düsseldorfer Orthorexia Scale (DOS) [64] and the Teruel Orthorexia Scale (TOS) [65]. Validation of each approach as a function of attentional preference for relevant stimuli would be a useful addition to the literature. However, given that recent work argues for the dissociation in food choice motivations between so-called healthy ON (an interest in healthy eating) and ON (a pathology characterized by the pre-occupation with healthy eating) [66], and that this distinction is articulated fully in the development of the TOS, future work should examine the nature of any observed bias in information processing as further evidence for any possible cognitively based indices. A second potential limitation refers to the fact that the stimuli used in the Stroop task may not fully match individual differences in the importance ascribed to these stimuli. It is possible that those with more pronounced $\mathrm{ON}$ are "influenced" by a different set of stimuli compared to those with a less pathological profile. Finally, whilst our findings suggest an attentional preference for healthy 
food-related words, other measures of attentional bias and allocation of attentional resources should be adopted in future work. For example, use of eye-tracking technology would enable the study of how individuals with and without an ON profile initially orientate attention towards relevant stimuli and whether these individuals are able to disengaged from such stimuli once attended to. Such work would provide useful insights for articulating a cognitive understanding of ON tendencies.

Overall, it appears that attentional preference for healthy food-related stimuli is characteristic of individuals with increasing ON-related tendencies. That such attentional preference adds significant additional explanatory power above any effects observed for change in hunger status suggests an independent relationship. Future work is required to replicate and validate this finding utilizing alternative measures of attentional allocation (e.g. dot probe tasks, eye-tracking technologies) and to examine, for example, initial orientation and gaze maintenance/delayed disengagement processes as further potential discriminatory factors.

Author contributions IA, MM, TM, and MS contributed to the design, analysis, and interpretation of the data. IA drafted the manuscript and MM, TM and MS commented on drafts. IA and MM contributed to the acquisition of the data.

Funding No funding was received for this study.

\section{Compliance with ethical standards}

Conflict of interest We declare that we do not have any commercial or associative interest that represents a conflict of interest in connection with the work submitted.

Ethical approval The Ethics Committee of London South Bank University approved the study. This study was performed fulfilling the principles of the British Psychological Society.

Informed consent Informed consent was obtained from all participants included in the study.

Open Access This article is distributed under the terms of the Creative Commons Attribution 4.0 International License (http://creativeco mmons.org/licenses/by/4.0/), which permits unrestricted use, distribution, and reproduction in any medium, provided you give appropriate credit to the original author(s) and the source, provide a link to the Creative Commons license, and indicate if changes were made.

\section{References}

1. Chaki B, Pal S, Bandyopadhyay A (2013) Exploring scientific legitimacy of orthorexia nervosa: a newly emerging eating disorder. J Hum Sport Exerc 8(4):1045-1053
2. Fidan T, Ertekin V, Işikay S, Kirpinar I (2010) Prevalence of orthorexia among medical students in Erzurum. Turk Compr Psychiatry 51(1):49-54

3. Asil E, Sürücüoğlu MS (2015) Orthorexia nervosa in Turkish dietitians. Ecol Food Nutr 54(4):303-313

4. Alvarenga MS, Martins MCT, Sato KSCJ, Vargas SVA, Philippi ST, Scagliusi FB (2012) Orthorexia nervosa behavior in a sample of Brazilian dietitians assessed by the Portuguese version of ORTO-15. Eat Weight Disord 17(1):e29-e35

5. Bosi ATB, Çamur D, Güler Ç (2007) Prevalence of orthorexia nervosa in resident medical doctors in the faculty of medicine (Ankara, Turkey). Appetite 49(3):661-666

6. Aksoydan E, Camci N (2009) Prevalence of orthorexia nervosa among Turkish performance artists. Eat Weight Disord 14(1):33-37

7. Segura-García C, Papaianni MC, Caglioti F, Procopio L, Nisticò CG, Bombardiere L, Ammendolia A, De Fazio P, Capranica L (2012) Orthorexia nervosa: a frequent eating disordered behavior in athletes. Eat Weight Disord 17(4):226-233

8. Valera JH, Ruiz PA, Valdespino BR, Visioli F (2014) Prevalence of orthorexia nervosa among ashtanga yoga practitioners: a pilot study. Eat Weight Disord 19(4):469-472

9. Hyrnik J, Janas-Kozik M, Stochel M, Jelonek I, Siwiec A, Krysta K, Rybakowski JK (2016) Prevalence of orthorexia nervosa among polish adolescents: assessment made by the ORTO-15 Questionnaire. Eur Psychiatry 33:S532

10. Sanlier N, Yassibas E, Bilici S, Sahin G, Celik B (2016) Does the rise in eating disorders lead to increasing risk of orthorexia nervosa? correlations with gender, education, and body mass index. Ecol Food Nutr 55(3):266-278

11. Bratman S, Knight D (2000) Health food junkies. Orthorexia nervosa: overcoming the obsession with healthful eating. Broadway Books, Estados Unidos, pp 25-38

12. Dunn TM, Bratman S (2016) On orthorexia nervosa: a review of the literature and proposed diagnostic criteria. Eat Behav 21:11-17

13. Vandereycken W (2011) Media hype, diagnostic fad or genuine disorder? Professionals' opinions about night eating syndrome, orthorexia, muscle dysmorphia, and emetophobia. Eat Disord 19(2): 145-155

14. Varga M, Dukay-Szabó S, Túry F, van Furth Eric F (2013) Evidence and gaps in the literature on orthorexia nervosa. Eat Weight Disord 18(2):103-111

15. Zickgraf HF, Ellis JM, Essayli JH (2019) Disentangling orthorexia nervosa from healthy eating and other eating disorder symptoms: relationships with clinical impairment, comorbidity, and selfreported food choices. Appetite 134:40-49

16. Koven NS, Senbonmatsu R (2013) A neuropsychological evaluation of orthorexia nervosa. Open J Psychiatry 3(02):214-222

17. Brytek-Matera A, Rogoza R, Gramaglia C, Zeppegno P (2015) Predictors of orthorexic behaviours in patients with eating disorders: a preliminary study. BMC Psychiatry 15(1):252-255

18. Koven NS, Abry AW (2015) The clinical basis of orthorexia nervosa: emerging perspectives. Neuropsychiatr Dis Treat 11:385-394

19. Brytek-Matera A (2012) Orthorexia nervosa: an eating disorder, obsessive-compulsive disorder or disturbed eating habit. Arch Psychiatry Psychother 1(1):55-60

20. Getz L (2009) Orthorexia: when eating healthy becomes an unhealthy obsession. Today's Dietit 11(6):40

21. Musolino C, Warin M, Wade T, Gilchrist P (2015) 'Healthy anorexia': the complexity of care in disordered eating. Soc Sci Med 139:18-25

22. Blechert J, Ansorge U, Tuschen-Caffier B (2010) A body-related dot-probe task reveals distinct attentional patterns for bulimia nervosa and anorexia nervosa. J Abnorm Psychol 119(3):575-585 
23. Eriksson L, Baigi A, Marklund B, Lindgren EC (2008) Social physique anxiety and sociocultural attitudes toward appearance impact on orthorexia test in fitness participants. Scand J Med Sci Sports 18(3):389-394

24. Håman L, Barker-Ruchti N, Patriksson G, Lindgren EC (2015) Orthorexia nervosa: an integrative literature review of a lifestyle syndrome. Int J Qual Stud Health Well-Being 10(1):26799

25. Moroze RM, Dunn TM, Holland JC, Yager J, Weintraub P (2015) Microthinking about micronutrients: a case of transition from obsessions about healthy eating to near-fatal "orthorexia nervosa" and proposed diagnostic criteria. Psychosomatics 56(4):397-403

26. Cinosi E, Matarazzo I, Marini S, Acciavatti T, Lupi M, Corbo M, Santaxcroce R, Vellante F, Sarchione F, De Berardis D, Carano A, Di Iorio G, Martinotti G, Di Giannantonio M (2015) Prevalence of orthorexia nervosa in a population of young Italian adults. Eur Psychiatry 30:1330

27. Poyraz CA, Tüfekçioğlu EY, Özdemir A, Baş A, Kani AS, Erginöz E, Duran A (2015) Relationship between orthorexia and obsessivecompulsive symptoms in patients with generalised anxiety disorder, panic disorder and obsessive-compulsive disorder. Yeni Symp 53(4):22-26

28. Barnes MA, Caltabiano ML (2017) The interrelationship between orthorexia nervosa, perfectionism, body image and attachment style. Eat Weight Disord 22(1):177-184

29. MacEvilly C (2001) The price of perfection. Nutr Bull 26(4):275-276

30. Rangel C, Dukeshire S, MacDonald L (2012) Diet and anxiety. An exploration into the orthorexic society. Appetite 58(1):124-132

31. Barthels F, Meyer F, Pietrowsky R (2018) Orthorexic and restrained eating behaviour in vegans, vegetarians, and individuals on a diet. Eat Weight Disord 23:159-166

32. Hayatbini N, Oberle CD (2019) Are orthorexia nervosa symptoms associated with cognitive inflexibility? Psychiatry Res 271:464-468

33. Smeets E, Roefs A, van Furth E, Jansen A (2008) Attentional bias for body and food in eating disorders: increased distraction, speeded detection, or both? Behav Res Ther 46(2):229-238

34. Harrison A, Sullivan S, Tchanturia K, Treasure J (2010) Emotional functioning in eating disorders: attentional bias, emotion recognition and emotion regulation. Psychol Med 40(11):1887-1897

35. Schmitz F, Naumann E, Trentowska M, Svaldi J (2014) Attentional bias for food cues in binge eating disorder. Appetite 80:70-80

36. Albery IP, Wilcockson T, Frings D, Moss AC, Caselli G, Spada MM (2016) Examining the relationship between selective attentional bias for food-and body-related stimuli and purging behaviour in bulimia nervosa. Appetite 107:208-212

37. Mathews A, MacLeod C (2005) Cognitive vulnerability to emotional disorders. Ann Rev Clin Psychol 1:167-195

38. Field M, Cox WM (2008) Attentional bias in addictive behaviors: a review of its development, causes, and consequences. Drug Alcohol Depend 97(1):1-20

39. Franken IH (2003) Drug craving and addiction: integrating psychological and neuropsychopharmacological approaches. Prog NeuroPsychopharmacol Biol Psychiatry 27(4):563-579

40. Field M, Munafo MR, Franken IH (2009) A meta-analytic investigation of the relationship between attentional bias and subjective craving in substance abuse. Psychol Bull 135(4):589-607

41. McCusker CG (2001) Cognitive biases and addiction: an evolution in theory and method. Addiction 96(1):47-56

42. Sheeran P, Gollwitzer PM, Bargh JA (2013) Nonconscious processes and health. Health Psychol 32(5):460-473

43. Dobson KS, Dozois DJ (2004) Attentional biases in eating disorders: a meta-analytic review of Stroop performance. Clin Psychol Rev 23(8):1001-1022

44. Freijy T, Mullan B, Sharpe L (2014) Food-related attentional bias. Word versus pictorial stimuli and the importance of stimuli calorific value in the dot probe task. Appetite 83:202-208
45. Phaf RH, Kan KJ (2007) The automaticity of emotional Stroop: a meta-analysis. J Behav Ther Exp Psychiatry 38(2):184-199

46. Kemps E, Tiggemann M, Martin R, Elliott M (2013) Implicit approach: avoidance associations for craved food cues. J Exp Psychol Appl 19(1):30-38

47. Paslakis G, Kühn S, Schaubschläger A, Schieber K, Röder K, Rauh E, Erim Y (2016) Explicit and implicit approach vs. avoidance tendencies towards high vs. low calorie food cues in patients with anorexia nervosa and healthy controls. Appetite 107:171-179

48. Calitri R, Pothos EM, Tapper K, Brunstrom JM, Rogers PJ (2010) Cognitive biases to healthy and unhealthy food words predict change in BMI. Obesity 18(12):2282-2287

49. Brytek-Matera A, Donini LM, Krupa M, Poggiogalle E, Hay P (2015) Orthorexia nervosa and self-attitudinal aspects of body image in female and male university students. J Eat Disord 1(3):1-8

50. Tabachnick BG, Fidell LS (2001) Using multivariate statistics, vol 5. Allyn \& Bacon, MA

51. Donini LM, Marsili D, Graziani MP, Imbriale M, Cannella C (2005) Orthorexia nervosa: validation of a diagnosis questionnaire. Eat Weight Disord 10:28-32

52. Nijs IM, Muris P, Euser AS, Franken IH (2010) Differences in attention to food and food intake between overweight/obese and normalweight females under conditions of hunger and satiety. Appetite $54(2): 243-254$

53. Werthmann J, Jansen A, Roefs A (2015) Worry or craving? A selective review of evidence for food-related attention biases in obese individuals, eating-disorder patients, restrained eaters and healthy samples. Proc Nutr Soc 74(2):99-114

54. Hou R, Mogg K, Bradley BP, Moss-Morris R, Peveler R, Roefs A (2011) External eating, impulsivity and attentional bias to food cues. Appetite 56(2):424-427

55. Cox WM, Klinger E, Fadardi JS (2015) The motivational basis of cognitive determinants of addictive behaviors. Addict Behav 44:16-22

56. Wiers RWHJ, Houben KMPI, Roefs AJ, De Jong P, Hofmann W, Stacy A (2010) Implicit cognition in health psychology: why common sense goes out of the window. In: Gawronski B, Payne BK (eds) Handbook of implicit social cognition: measurement, theory, and applications. Guilford Press, New York, pp 463-488

57. Hardman CA, Rogers PJ, Etchells KA, Houstoun KV, Munafò MR (2013) The effects of food-related attentional bias training on appetite and food intake. Appetite 71:295-300

58. Schmitz F, Svaldi J (2017) Effects of bias modification training in binge eating disorder. Behav Ther 48(5):707-717

59. Kennedy AP, Gross RE, Ely T, Drexler KP, Kilts CD (2014) Clinical correlates of attentional bias to drug cues associated with cocaine dependence. Am J Addict 23(5):478-484

60. Mitchell MR, Balodis IM, DeVito EE, Lacadie CM, Yeston J, Scheinost D, Comstable RT, Carroll KM, Potenza MN (2013) A preliminary investigation of Stroop-related intrinsic connectivity in cocaine dependence: associations with treatment outcomes. Am J Drug Alcohol Abuse 39(6):392-402

61. Mogg K, Bradley B, Miles F, Dixon R (2004) Brief report time course of attentional bias for threat scenes: testing the vigilanceavoidance hypothesis. Cognit Emot 18(5):689-700

62. Roncero M, Barrada JR, Perpiñá (2017) Measuring orthorexia nervosa: psychometric limitations of the ORTO-15. Span J Psychol e41:1-9. https://doi.org/10.1017/sjp.2017.36

63. Gleaves DH, Graham EC, Ambwani S (2013) Measuring 'orthorexia': development of the Eating Habits Questionnaire. Int J Educ Psychol Assess 12:1-18

64. Barthels F, Meyer F, Pietrowsky R (2015) Duesseldorf Orthorexia Scale construction and evaluation of a questionnaire measuring orthorexic eating behavior. Z. Klin 44:97-105 
65. Barrada JR, Roncero M (2018) Bidimensional structure of the orthorexia: development and initial validation of a new instrument. Anales de Psicología 34:283-291

66. Depa J, Barrada JR, Roncero M (2019) Are the motives for food choices different in orthorexia nervosa and healthy orthorexia? Nutrients 11:697. https://doi.org/10.3390/nu11030697
Publisher's Note Springer Nature remains neutral with regard to jurisdictional claims in published maps and institutional affiliations. 